\title{
The comparison of Kardia Mobile and Hartmann Veroval 2 in 1 in detecting first diagnosed atrial fibrillation
}

\author{
Tomasz Zaprutko ${ }^{1}$, Joanna Zaprutko², Józefina Sprawka ${ }^{3}$, \\ Monika Pogodzińska ${ }^{3}$, Michał Michalak ${ }^{4}$, Anna Paczkowska ${ }^{1}$, \\ Krzysztof Kus ${ }^{2}$, Elżbieta Nowakowska ${ }^{5}$, Artur Baszko ${ }^{2}$ \\ ${ }^{1}$ Department of Pharmacoeconomics and Social Pharmacy, \\ Poznan University of Medical Sciences, Poznan, Poland \\ ${ }^{2}$ Second Department of Cardiology, Poznan University of Medical Sciences, \\ HCP Medical Center, Poznan, Poland \\ ${ }^{3}$ Student Scientific Society, Department of Pharmacoeconomics and Social Pharmacy, \\ Poznan University of Medical Sciences, Poznan, Poland \\ ${ }^{4}$ Department of Computer Sciences and Statistics, \\ Poznan University of Medical Sciences, Poznan, Poland \\ ${ }^{5}$ Department of Pharmacology and Toxicology, University of Zielona Góra, Poland
}

\begin{abstract}
Background: Atrial fibrillation $(A F)$ is the leading cause of stroke. The European Society of Cardiology (ESC) advises opportunistic AF screening among patients aged $\geq 65$ years. Considering this, the aim herein, was compare the feasibility of two different systems of smartphone-based electrocardiogram (ECG) recordings to identify $A F$ among those without a previous arrhythmia history.

Methods: Prospective AF screening was conducted at six pharmacies using Kardia Mobile and Hartmann Veroval 2 in 1. A single-lead ECG was acquired by the placement of fingers on the pads. A cardiologist evaluated findings from both devices.

Results: Atrial fibrillation was identified in $3.60 \%$ and previously unknown AF was detected in $1.92 \%$ of the study participants. Sensitivity and specificity of the Kardia application in detecting AF were 66.7\% (95\% confidence interval [CI] 38.4-88.2\%) and 98.5\% (95\% CI 96.7-99.5\%), and for Veroval $10.0 \%$ (95\% CI 0.23-44.5\%) and $94.96 \%$ (95\% CI 92.15-96.98\%), accordingly. Inter-rater agreement was $k=0.088(95 \%$ CI 1.59-16.1\%).

Conclusions: Mobile devices can detect AF, but each finding must be verified by a professional. The Kardia application appeared to be more user-friendly than Veroval. Cardiovascular screening using mobile devices is feasible at pharmacies. Hence it might be considered for routine use. (Cardiol J)
\end{abstract}

Key words: atrial fibrillation, mobile devices, screening, pharmacies, new technologies

Address for correspondence: Tomasz Zaprutko, PhD, MP, Department of Pharmacoeconomics and Social Pharmacy, Poznan University of Medical Sciences, ul. Rokietnicka 7, 60-806 Poznań, Poland, tel/fax: +48 6184526 84, e-mail: tomekzaprutko@ump.edu.pl

Received: 15.03.2021 Accepted: 8.07.2021 Early publication date: 2.08.2021

This article is available in open access under Creative Common Attribution-Non-Commercial-No Derivatives 4.0 International (CC BY-NC-ND 4.0) license, allowing to download articles and share them with others as long as they credit the authors and the publisher, but without permission to change them in any way or use them commercially. 


\section{Introduction}

Atrial fibrillation (AF) affects up to 34 million people worldwide $[1,2]$. It is the most common cardiac arrhythmia with a prevalence of $1.5-2.0 \%$ in the general population. AF incidence has increased to almost $6 \%$ for those above 65 and $8.8 \%$ for those more than 80 years old [3-5]. AF is also the leading cause of stroke [1]. In many cases AF is asymptomatic and in $25 \%$ of patients, it is diagnosed after a thromboembolic event $[1,6,7]$. Thus, it contributes to the significant economic and public health burden, with annual costs accounting for more than 6.5 billion dollars in the United States [5, 6, 8-10].

Because the world's population is aging quickly $[11,12]$, the prevalence of $\mathrm{AF}$ is expected to double by 2060 [3]. One of the main challenges for healthcare is identifying AF as early as possible before a thromboembolic event occurs. There is a lot of data showing that adequate anticoagulation treatment reduces thromboembolic complications $[3,13]$. The European Society of Cardiology (ESC) advises opportunistic $\mathrm{AF}$ screening in combination with the $\mathrm{CHA}_{2} \mathrm{DS}_{2}$-VASc score (Score for Atrial Fibrillation Stroke Risk [Congestive heart failure, Hypertension, Age $\geq 75$, Diabetes mellitus, Stroke, Vascular disease, Age 65-74, Sex]) among patients aged $\geq 65$ years $[14,15]$. Although it is still not routinely performed $[16,17]$, new technologies such as mobile electrocardiogram (ECG) devices may facilitate the implementation of common $\mathrm{AF}$ screening $[16,18]$. These technologies can detect $\mathrm{AF}[16,17,19,20]$ and are both convenient and inexpensive $[11,21]$. In their studies, Lowres et al. [19] and Zaprutko et al. [17] confirmed the feasibility of AF detection using mobile ECG in public places (e.g., pharmacies). They identified an incidence of $\mathrm{AF}$ in $1.5 \%$ and $1.33 \%$ of subjects without previous history of arrhythmia in Australia and Poland, respectively $[17,19]$. Besides, Lowres et al. [19, 20] reported Kardia Mobile to be cost-effective in screening patients for $\mathrm{AF}$ at pharmacies.

The objective of the present prospective study was to compare the feasibility of two different systems in identifying $\mathrm{AF}$ among those without a previous arrhythmia history. For that purpose, two different technologies were evaluated; Kardia Mobile with a dedicated smartphone application (app) and Hartmann Veroval 2 in 1 - ECG and Blood Pressure Monitor.

\section{Methods}

Atrial fibrillation screening was carried out between December 2018 and February 2020 at
6 pharmacies located in different regions of Poland. The study was approved by the Bioethics Committee of Poznan University of Medical Sciences and by the pharmacy owners who agreed to conduct the research.

Pharmacists, cardiologists, and students from the Student Scientific Society of Pharmacoeconomics and Social Pharmacy made up the research team. Students and non-physician researchers took part in a course on the basics of the used devices, thromboembolic risk assessment (the $\mathrm{CHA}_{2} \mathrm{DS}_{2}$ -VASc score), and ECG basics.

The Kardia Mobile with a Kardia app (iOS/Android) is the Food and Drug Administration (FDA) approved device for recording, storing, and transfer of single-channel lead ECGs $[16,19]$.

A single-lead ECG from Kardia Mobile was acquired by placing fingers of both hands on the device pads for $30 \mathrm{~s}$. The ECG's electrical signals were modified to an ultrasonic frequency modulation sound signal and then transmitted to a smartphone with the installed Kardia app [6]. The program demodulated the signal to a digital ECG trace (300 samples/s, 16-bit resolution), displayed it in real-time on the smartphone screen, and then transmitted and stored it on a password-protected server [22].

Veroval is dedicated to blood pressure measurement and for mobile ECG recording and conforms to European regulations based on the European Medical Device Directive 93/42/EEC. It bears the Conformité Européenne mark [23].

In this system, an ECG recording is acquired by placing a finger from the right hand on the upper electrode and one finger from the left hand on the lower electrode of the device. Veroval switches on automatically when the two fingers are placed on the electrodes. If the "ECG" notification appears on display, the device starts to record an ECG for 30 -s. When the recording is complete, the final ECG finding appears on display but the tracing is not visible. To over-read Veroval's recordings, tracings are transferred via Bluetooth to software (Veroval medi.connect) on the user's computer.

Kardia provided 7 and Veroval 8 possible findings presented in Table 1 [22-25].

\section{Inclusion criteria}

Each patient visiting a pharmacy who looked to be 65 or more was asked to join the study. Younger patients or those with the previous history of $\mathrm{AF}$ were excluded from the study. A written informed consent with the patient's phone number and $\mathrm{CHA}_{2} \mathrm{DS}_{2}$-VASc score was collected. Finally, an ECG was performed. 
Table 1. Possible Kardia and Veroval findings.

\begin{tabular}{|c|c|c|c|}
\hline \multicolumn{2}{|r|}{ Kardia possible findings } & \multicolumn{2}{|c|}{ Veroval possible findings } \\
\hline ECG finding & Description & ECG finding & Description \\
\hline POSSIBLE AF & $\begin{array}{l}\text { AF was detected based on of P-wave } \\
\text { absence and } R-R \text { interval irregularity }\end{array}$ & OK & Normal ECG recording \\
\hline NORMAL & $\begin{array}{l}\text { The HR was regular and } \\
\text { between } 50 \text { and } 100 \mathrm{bpm} \text {, with } \\
\text { shape, timing, and duration of every } \\
\text { beat considered normal }\end{array}$ & FAST & HR was higher than $100 \mathrm{bpm}$ \\
\hline UNCLASSIFIED & $\begin{array}{l}\text { The quality of tracing was good but } \\
\text { the Kardia application could not } \\
\text { differentiate between "possible AF", } \\
\text { and "normal" recordings (e.g., irregular } \\
\text { rhythm due to premature complexes) }\end{array}$ & SLOW & HR was lower than $55 \mathrm{bpm}$ \\
\hline UNREADABLE & $\begin{array}{l}\text { Resulted from poor ECG quality } \\
\text { (e.g., due to sound or electrical } \\
\text { interference) }\end{array}$ & PAUSE & $\begin{array}{l}\text { One or more brakes in the heart } \\
\text { cycles that were longer than } 2 \mathrm{~s}\end{array}$ \\
\hline TACHYCARDIA & $\begin{array}{l}\text { Regular HR faster than } \\
100 \mathrm{bpm}\end{array}$ & RHYTHM & $\begin{array}{c}\text { During the ECG recording supra- } \\
\text { ventricular arrhythmia was detected } \\
\text { (AF, atrial flutter, pathological } \\
\text { sinus arrhythmia, paroxysmal atrial } \\
\text { tachycardia, or supraventricular } \\
\text { extrasystole) }\end{array}$ \\
\hline BRADYCARDIA & $\begin{array}{l}\text { Regular HR was less than } \\
50 \mathrm{bpm}\end{array}$ & WAVE & $\begin{array}{c}\text { A changed ECG wave shape occurred } \\
\text { (e.g., ventricular arrhythmias) }\end{array}$ \\
\hline \multirow[t]{2}{*}{ NO ANALYSIS } & $\begin{array}{l}\text { There was no finding presented } \\
\text { (e.g., due to the noise } \\
\text { on the signal) }\end{array}$ & $\begin{array}{l}\text { RHYTHM and } \\
\text { WAVE }\end{array}$ & $\begin{array}{l}\text { Indicated arrhythmia with changed } \\
\text { wave shape (including singular } \\
\text { ventricular extrasystole, bigeminy, } \\
\text { trigemini, series of ventricular } \\
\text { extrasystole, multifocal ventricular } \\
\text { extrasystole, and ventricular } \\
\text { tachycardia }\end{array}$ \\
\hline & & ERROR & $\begin{array}{l}\text { Occurs e.g., if there was insufficient } \\
\text { skin contact to the upper and } \\
\text { lower electrodes }\end{array}$ \\
\hline
\end{tabular}

$\mathrm{AF}$ - atrial fibrillation; $\mathrm{ECG}$ - electrocardiogram; $\mathrm{HR}$ - heart rate

\section{ECG recording}

Each time, an ECG with the Kardia app was recorded first, followed by Veroval. ECG recordings from Kardia were saved as PDF files and password protected. For Veroval, the recordings were saved by the device (up to 64 measurements) and subsequently transferred via Bluetooth directly to the dedicated software.

Stored ECG recordings were analyzed by cardiologists (after logging in). One of the cardiologists analyzed the recordings and gave a diagnosis of "AF", "non-AF," or "non-interpretable". If artifacts were present on the ECG recording or there was no ECG tracing despite the ECG finding presented on Veroval's display, the recording was evaluated as "non-interpretable". If the cardiologist had doubts about the diagnosis a second cardiologist was consulted with the tracing to provide a final diagnosis.
If the cardiologist diagnosed $\mathrm{AF}$, the patient was contacted by phone and advised to contact their general practitioner for a further evaluation. All of the patients were presented with an option to get their ECG tracing by e-mail or to pick up a printout at the pharmacy where it had been carried out (Suppl. Figs. 1-3).

\section{Statistical analysis}

A comparison of an AF diagnosis made by the analyzed application and the cardiologist was performed using the Fisher exact test. The sensitivity and specificity, and predictive powers were calculated for the Kardia app, and Veroval took the cardiologist's diagnosis as the gold standard. The Bland-Altman plot was used to describe the agreement between heart rates recorded by the applications. The difference in mean heart rate (HR) 
values was tested by using the paired t-Student test. Additionally, the kappa coefficient was calculated to assess the agreement in the diagnosis of $\mathrm{AF}$ between the analyzed applications (inter-rater agreement).

Statistical analysis was performed using TIBCO Software Inc. (2017) and Statistica (data analysis software system), version 13 . All tests were considered significant for $\mathrm{p}<0.05$.

\section{Results}

Out of 878 potential participants asked to join the study, 230 refused, and 115 were younger than 65. Moreover, 94 patients were excluded due to their previous arrhythmia diagnoses, inability to fulfil the $\mathrm{CHA}_{2} \mathrm{DS}_{2}-\mathrm{VASc}$ protocol, or refusal to be subjected to a second (Veroval) ECG recording. In addition, 22 patients were excluded from further analysis because they could not operate the device, e.g., due to shaking hands. Finally, 417 patients were included in the study, and the study group structure is presented in Table 2 . In addition, a distribution of the findings from the Kardia app and Veroval and cardiologists' diagnoses is presented in Tables 3 and 4.

After the over-read of each recording (Kardia first followed by tracings from Veroval), AF was identified in $15(3.60 \%)$ patients. However, the cardiologist's interview revealed 7 (1.68\%) patients admitted to the AF history. Hence, the study identified $8(1.92 \%)$ patients with newly diagnosed AF. Importantly, due to the different quality of tracings, the Kardia app allowed us to detect 15 AF cases, whereas Veroval revealed 10. Inter-rater agreement (kappa coefficient) between the devices was $\mathrm{k}=0.088$ (95\% confidence interval $[\mathrm{CI}] 1.59-16.1 \%$ ).

Sensitivity and specificity of the Kardia app in detecting AF were $66.7 \%$ (95\% CI 38.4-88.2\%) and 98.5\% (95\% CI 96.7-99.5\%), respectively. Positive predictive value (PPV) and negative predictive value (NPV) were $62.5 \%$ (95\% CI 35.4-84.8\%) and 98.7\% (95\% CI 97.1-99.6\%), respectively.

For Veroval the sensitivity and specificity of detecting AF were $10.0 \%$ (95\% CI $0.23-44.5 \%$ ) and $94.96 \%$ (95\% CI 92.15-96.98\%), accordingly. PPV and NPV were $5.23 \%$ (95\% CI 0.12-26.03\%) and $97.41 \%$ (95\% CI 95.15-98.81\%), respectively.

Atrial fibrillation diagnosed by a cardiologist was frequently classified by Veroval as ventricular arrhythmia (simultaneous "rhythm" and "wave" finding). It resulted from the presence of isoelectric line artifacts (also unknown), which the device identified as changed wave shapes. Hence,

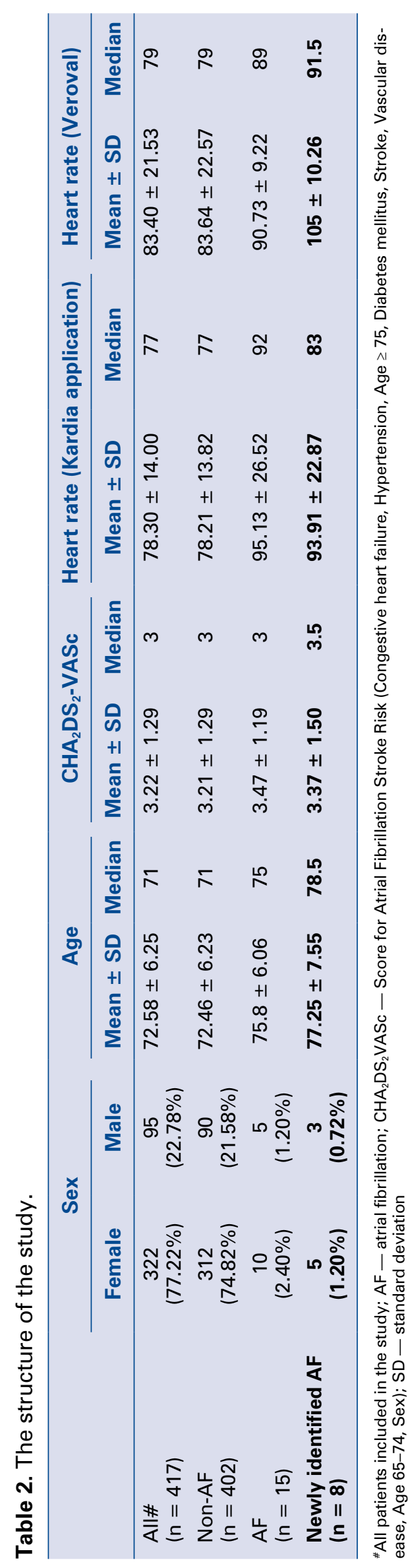


Table 3. Findings from Kardia application $(n=417)$ and diagnoses after the cardiologist's over-read.

\begin{tabular}{|c|c|c|c|}
\hline \multicolumn{2}{|c|}{ Kardia application findings } & \multicolumn{2}{|c|}{ After cardiologists over-read } \\
\hline Kardia finding & Number of findings & Diagnosis & Number of findings \\
\hline Normal & $347(83.21 \%)$ & $\begin{array}{l}\text { Non-AF } \\
\text { AF } \\
\text { Non-interpretable }\end{array}$ & $\begin{array}{c}343(98.85 \%) \\
1(0.29 \%) \\
3(0.86 \%)\end{array}$ \\
\hline Possible AF & $16(3.84 \%)$ & $\begin{array}{l}\text { Non-AF } \\
\text { AF } \\
\text { Non-interpretable }\end{array}$ & $\begin{array}{c}4(25 \%) \\
10(62.5 \%) \\
2(12.5 \%)\end{array}$ \\
\hline Unclassified & $34(8.15 \%)$ & $\begin{array}{l}\text { Non-AF } \\
\text { AF } \\
\text { Non-interpretable }\end{array}$ & $\begin{array}{c}26(76.47 \%) \\
2(5.88 \%) \\
6(17.65 \%)\end{array}$ \\
\hline Unreadable & $8(1.92 \%)$ & $\begin{array}{l}\text { Non-AF } \\
\text { AF } \\
\text { Non-interpretable }\end{array}$ & $\begin{array}{c}3(37.5 \%) \\
- \\
5(62.5 \%)\end{array}$ \\
\hline Tachycardia & $6(1.44 \%)$ & $\begin{array}{l}\text { Non-AF } \\
\text { AF } \\
\text { Non-interpretable }\end{array}$ & $\begin{array}{c}5(83.33 \%) \\
1(16.67 \%) \\
-\end{array}$ \\
\hline No analysis & $2(0.48 \%)$ & $\begin{array}{l}\text { Non-AF } \\
\text { AF } \\
\text { Non-interpretable }\end{array}$ & $\begin{array}{c}1(50 \%) \\
1(50 \%) \\
-\end{array}$ \\
\hline Without notification & $4(0.96 \%)$ & $\begin{array}{l}\text { Non-AF } \\
\text { AF } \\
\text { Non-interpretable }\end{array}$ & $\begin{array}{c}4(100 \%) \\
- \\
-\end{array}$ \\
\hline
\end{tabular}

$\mathrm{AF}$ - atrial fibrillation

Table 4. Findings from Veroval $(n=417)$ and diagnoses after the cardiologist's over-read.

\begin{tabular}{|c|c|c|c|}
\hline \multicolumn{2}{|c|}{ Veroval findings } & \multicolumn{2}{|c|}{ After cardiologists over-read } \\
\hline Veroval finding & Number of findings & Diagnosis & Number of findings \\
\hline Rhythm & $19(4.56 \%)$ & $\begin{array}{l}\text { Non-AF } \\
\text { AF } \\
\text { Non-interpretable } \\
\text { Lack of tracing }\end{array}$ & $\begin{array}{c}16(84.21 \%) \\
1(5.26 \%) \\
2(10.53 \%) \\
-\end{array}$ \\
\hline Rhythm/Wave & $84(20.14 \%)$ & $\begin{array}{l}\text { Non-AF } \\
\text { AF } \\
\text { Non-interpretable } \\
\text { Lack of tracing }\end{array}$ & $\begin{array}{c}39(46.43 \%) \\
8(9.52 \%) \\
31(36.91 \%) \\
6(7.14 \%)\end{array}$ \\
\hline Ok & $259(62.11 \%)$ & Non-AF & $235(90.73 \%)$ \\
\hline Fast & $37(8.87 \%)$ & $\begin{array}{l}\text { AF } \\
\text { Non-interpretable } \\
\text { Lack of tracing } \\
\text { Non-AF }\end{array}$ & $\begin{array}{c}1(0.39 \%) \\
1(0.39 \%) \\
22(8.49 \%) \\
12(32.43 \%)\end{array}$ \\
\hline Slow & $7(1.68 \%)$ & $\begin{array}{l}\text { AF } \\
\text { Non-interpretable } \\
\text { Lack of tracing } \\
\text { Non-AF }\end{array}$ & $\begin{array}{c}- \\
19(51.35 \%) \\
6(16.22 \%) \\
7(100 \%)\end{array}$ \\
\hline & & AF & - \\
\hline Error & $11(2.64 \%)$ & $\begin{array}{l}\text { Non-interpretable } \\
\text { Lack of tracing } \\
\text { Non-AF } \\
\text { AF } \\
\text { Non-interpretable } \\
\text { Lack of tracing }\end{array}$ & $\begin{array}{c}- \\
- \\
- \\
- \\
- \\
11(100 \%)\end{array}$ \\
\hline
\end{tabular}

$\mathrm{AF}$ - atrial fibrillation 


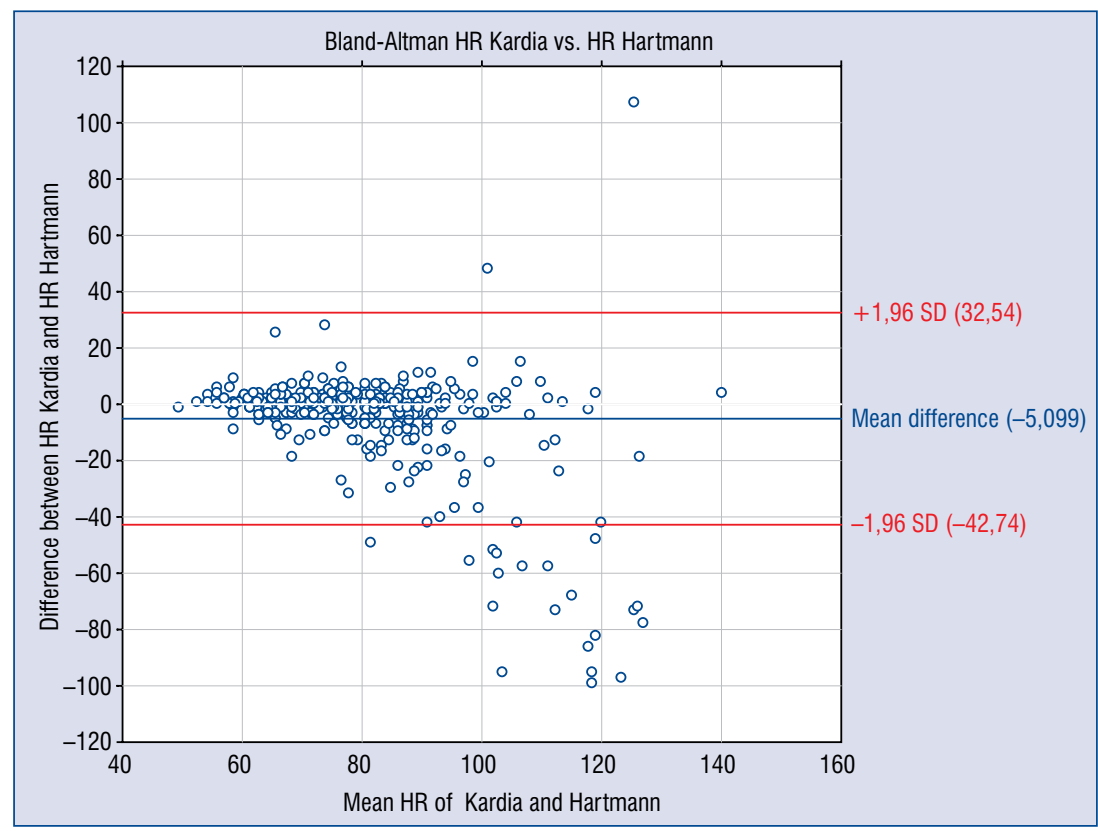

Figure 1. The agreement between heart rates recorded by Kardia application and Veroval; HR — heart rate.

considering "rhythm" and simultaneous "rhythm" and "wave" findings collectively and as a warning of supraventricular or ventricular arrhythmias, the sensitivity and specificity in detecting AF were 90.0\% (95\% CI 55.52-99.75\%) and $74.79 \%$ (95\% CI 69.93-79.18\%), respectively. The PPV and NPV were $9.09 \%$ (95\% CI $4.25-16.55 \%$ ) and $99.63 \%$ (95\% CI 97.94-99.99\%) respectively.

The mean heart rate for the Kardia app was $78.30 \pm 14.00$; median 77 and for Veroval it was $83.40 \pm 21.53$; median $79(\mathrm{p}<0.001)$. The distribution of heart rate results is presented on the Bland-Altmann plot (Fig. 1).

\section{Discussion}

The most important result of the present study was that $\mathrm{AF}$ was identified in $3.60 \%$ of patients. Previously unknown AF was detected in $1.92 \%$ of the study participants. The Kardia app achieved this with an acceptable level of sensitivity and high specificity. For Veroval, the sensitivity was low, but specificity was high. According to the McHugh [26] study about inter-rater reliability, the $\mathrm{k}$ coefficient between the used devices was very low $(\mathrm{k}=0.088)$.

Current results of new AF detection are in line with other studies. For example, using the Kardia app, Zaprutko et al. [17] found previously unknown $\mathrm{AF}$ in $1.33 \%$ of patients. In turn, Lowres et al. [19], and Halcox et al. [27] revealed new $\mathrm{AF}$ in $1.5 \%$ and
$1.84 \%$ of individuals, respectively. In the review provided by Ramkumar et al. [28], the average AF detection rate using portable ECG monitoring was $1.7 \%$ (95\% CI $1.4-2.1 \%$ ).

In the present study, the sensitivity of the Kardia app was $66.77 \%$. Alternatively, Zaprutko et al. [17] and Koshy et al. [29] revealed a sensitivity of $100 \%$. Lau et al. [22] reported a sensitivity of $98 \%$. A sensitivity of $(71.4 \%)$ was presented by Chan et al. [16], this was close to the present result, but Desteghe et al. [30] reported sensitivity of the Kardia app at $36.8 \%$. Thus, specificity was high in the current study and was in line with results revealed by Zaprutko et al. (98.7\%), Lau et al. (97.0\%), and William et al. (94.1\%) [17, 22, 31].

The Kardia app's PPV (62.5\%) was lower than the result revealed, e.g., by Selder et al. (80\%) [32]. PPV for Veroval (5.23\%) was very low, and it was probably the effect of common artifacts in ECG tracings. Low PPV might be a drawback of portable ECG devices because they rely on a patient's ability to perform the test accurately. The device might interpret any noise during an ECG recording as arrhythmia. These devices provide a finding, not a diagnosis, and all those true and false-positive tests should be re-evaluated by professionals [16]. Contrary to PPV, both the Kardia app and Veroval achieved a very high level of NPV ( $\sim 99 \%)$. Chan et al. [16], screening tests should have both high specificity and NPV, and is convergent with the current results. 
During the last decade, there has been significant development of mobile health applications, with approximately 3.7 billion downloaded globally between 2013 and 2017. These included many for detecting AF. Despite this, only a few of the apps have undergone a formal assessment [33]. Although we used approved devices, a very low inter-rater agreement $(\mathrm{k}=0.088)$ between them was revealed. Contrary to this finding, Desteghe et al. [30] revealed no difference in the agreement between the Kardia app and MyDiagnostick (a handheld ECG device). It may result from differences in the methodology of these studies and automated algorithms used by the producers of such devices. Besides, Mant et al. [34] noticed that differences in diagnoses were possible when the interpretation was made by dedicated software or by different operators.

There was also a difference in heart rate measurements between devices (Table 1). Veroval was used as a second device in each case, so the study participants should have been calmer. However, Veroval provided higher heart rate results. Considering findings revealed by Coppetti et al. [35], this is not surprising. They noticed that in smartphone applications for heart rate measurement, a difference of over $20 \mathrm{bpm}$ occurred in more than $20 \%$ of all cases. Observed differences in bpm may also result from imperfections of the equipment used. For instance, Koshy et al. [36] found that smartwatches demonstrated strong agreement for heart rate estimation in sinus rhythm, but the value was surprisingly underestimated in $\mathrm{AF}$ patients.

In the current study, the $\mathrm{CHA}_{2} \mathrm{DS}_{2}$-VASc score was lower in the group of non-AF patients $(3.21 \pm$ $\pm 1.29)$ compared to those with newly identified $\mathrm{AF}$ $(3.37 \pm 1.51)$. Although it is in line with other studies, the difference obtained in the present study was lower than that revealed by Lowres et al. [19] $(3.2 \pm 1.1$ for non-AF participants and $3.7 \pm 1.1$ for those with newly identified AF) and by Yan et al. [3] (3.1 \pm 1.9 for non-AF participants and $4.5 \pm$ \pm 2.0 for those with present AF). Nevertheless, the presented results confirm that all $\mathrm{AF}$ patients are potential candidates for oral anticoagulants due to high stroke risk [19].

After a cardiologist assessment, there were 16 $(3.84 \%)$ non-interpretable Kardia app findings and $53(12.71 \%)$ such notifications from Veroval. The number of non-interpretable tracings may result from the fact that using the equipment for the first time could have been stressful for older people. Some issues may also have occurred due to the evaluation of ECG quality by non-professionals
$[30,37]$. Moreover, tracings from handheld devices often have an unstable baseline and noise [30].

Importantly, for Veroval, it was impossible to view the recording on display (only findings were presented) and thus, an evaluation of the tracing quality. Unfortunately, it was quite common ( $\mathrm{n}=45$; $10.79 \%$ ) that there was no ECG tracing after transferring an ECG recording to a computer, but the device provided a finding during the test.

The number of non-interpretable recordings from Veroval and those without tracings recorded might be the main reason for less (10 compared to 15 from the Kardia app) AF cases diagnosed after a cardiologist's evaluation. It could also partially explain the low $\mathrm{k}$ between devices. Besides, the number of Veroval's tracings of poor quality may partly result from the chosen recording method. For Veroval, the first-choice option is the "right index finger-chest", and the measurement stability is higher for this method. Despite this, the "left handright hand" method was chosen, which is more comfortable [23], and ensured that the measurement method by both devices was similar. Secondly, more patients were expected to refuse taking part if the recording would require partial undressing. However, electrodes pressed too firmly onto the skin, and the resulting muscle tension could lead to imprecisely measured values [23].

Ramkumar et al. [28] pointed out that the screening tool should also be affordable and cost-effective. Both devices might be considered inexpensive and enable numerous recording repetitions. The official price of Kardia Mobile is US\$ 89 (June 2020). External entities distribute Veroval; thus, the price might vary and is usually between US\$ 120 and US $\$ 145$ in Poland. Notably, several authors evaluated handheld ECG devices as cost-effective [14, 19, 30, 38]. For the Kardia app, Lowres et al. $[19,20]$ revealed an incremental cost-effectiveness ratio of $€ 3142$ per gained quality-adjusted life years (QALY). In turn, Jacobs et al. [4] showed that AF screening with a handheld mobile device provided an additional 0.27 QALYs with cost savings of EUR 764 per patient.

Despite possible advantages and drawbacks of mobile health technologies, the use of new technologies in AF screening may significantly impact the future of healthcare [39]. It could also support traditional healthcare delivery [33], especially during a pandemic. Furthermore, high specificity, high NPV, and affordability of the used devices may lead to the opportunistic AF screening becoming common and feasible, e.g., at pharmacies. Besides, formally evaluated apps and devices demonstrate 
improvements in patient knowledge of $\mathrm{AF}$ and oral anticoagulants. Hence, it contributes to medication adherence, a better quality of life, and more effective treatment [33].

\section{Limitations of the study}

The study sample could have been larger. However, the present study was suddenly stopped due to the COVID-19 pandemic. The subsequent lockdowns of the country and severely limited physical contact between people after the gradual opening of the national economy were significant obstacles for the study. Besides, the study was not advertised anywhere to avoid pharmacy advertising, which is unlawful in Poland [40, 41]. It would be worthwhile to conduct the screening with Veroval using the first-choice option from Veroval's manual to have a possibly better quality of recordings. Opportunistic and one-time ECG screening may miss patients with paroxysmal AF.

\section{Implications for future research}

Although both devices provide similar usefulness for ECG recordings, there are differences between them. In our opinion, the Kardia app is more user-friendly, i.e., the Veroval is more challenging to use. For the Kardia app, the transfer of recordings is more convenient, and the quality of recordings is better. Although smartphones are common right now [42, 43], Veroval, contrary to the Kardia app, does not require a smartphone to provide an ECG recording. However, tracing provided by Veroval is visible after transfer to the computer's software. Therefore, it does not allow one to evaluate if tracing is of good quality in an instant. Veroval is simultaneously a blood pressure monitor, which makes the device multifunctional. The low level of Veroval's sensitivity in detecting $\mathrm{AF}$ should be relevant motivation for the producer to improve the algorithms used for supraventricular arrhythmia/AF detection.

\section{Conclusions}

Atrial fibrillation was identified in $3.60 \%$ of patients and in $1.92 \%$ of patients ( $\geq 65$ years old) with a previously undiagnosed AF. Mobile devices are capable of detecting AF but with different levels of sensitivity and specificity. The very low interrater agreement between devices confirmed that each finding must be verified by a professional. The Kardia app appeared to be more user-friendly than Veroval. Due to a better quality of ECG tracings, cardiologists confirmed more new AF cases based on the tracings from the Kardia app than solely based on Veroval. Cardiovascular screening using mobile devices is feasible at pharmacies; hence it might be considered for routine use.

\section{Funding}

The study was supported by a grant from Paul Hartmann Polska Sp. z o.o. The funders had no role in study design, data collection, analysis, decision to publish, or manuscript preparation.

\section{Acknowledgments}

We thank Students from the Student Scientific Society of Pharmacoeconomics and Social Pharmacy for their engagement and interest in this study.

\section{Conflict of interest: None declared}

\section{References}

1. Tison GH, Sanchez JM, Ballinger B, et al. Passive detection of atrial fibrillation using a commercially available smartwatch. JAMA Cardiol. 2018; 3(5): 409-416, doi: 10.1001/jamacardio.2018.0136, indexed in Pubmed: 29562087.

2. Zulkifly H, Lip GYH, Lane DA. Epidemiology of atrial fibrillation. Int J Clin Pract. 2018; 72(3): e13070, doi: 10.1111/ijcp.13070, indexed in Pubmed: 29493854.

3. Yan BP, Lai WHS, Chan CKY, et al. Contact-free screening of atrial fibrillation by a smartphone using facial pulsatile photoplethysmographic signals. J Am Heart Assoc. 2018; 7(8), doi: 10.1161/JAHA.118.008585, indexed in Pubmed: 29622592.

4. Jacobs MS, Kaasenbrood F, Postma MJ, et al. Cost-effectiveness of screening for atrial fibrillation in primary care with a handheld, single-lead electrocardiogram device in the Netherlands. Europace. 2018; 20(1): 12-18, doi: 10.1093/europace/euw285, indexed in Pubmed: 27733465.

5. Coyne KS, Paramore C, Grandy S, et al. Assessing the direct costs of treating nonvalvular atrial fibrillation in the United States. Value Health. 2006; 9(5): 348-356, doi: 10.1111/j.15244733.2006.00124.x, indexed in Pubmed: 16961553.

6. White RD, Flaker G. Smartphone-based Arrhythmia Detection: Should we encourage patients to use the ECG in their pocket? J Atr Fibrillation. 2017; 9(6): 1605, doi: 10.4022/jafib.1605, indexed in Pubmed: 29250298.

7. Chan PH, Wong CK, Poh YC, et al. Diagnostic performance of a smartphone-based photoplethysmographic application for atrial fibrillation screening in a primary care setting. J Am Heart Assoc. 2016; 5(7), doi: 10.1161/JAHA.116.003428, indexed in Pubmed: 27444506 .

8. Demaerschalk BM, Hwang HM, Leung G. US cost burden of ischemic stroke: a systematic literature review. Am J Manag Care. 2010; 16(7): 525-533, indexed in Pubmed: 20645668.

9. Yoneda Y, Okuda S, Hamada R, et al. Hospital cost of ischemic stroke and intracerebral hemorrhage in Japanese stroke centers. Health Policy. 2005; 73(2): 202-211, doi: 10.1016/j.healthpol.2004.11.016, indexed in Pubmed: 15978963.

10. Zoni-Berisso M, Lercari F, Carazza T, et al. Epidemiology of atrial fibrillation: European perspective. Clin Epidemiol. 2014; 6: 213-220, doi: 10.2147/CLEP.S47385, indexed in Pubmed: 24966695. 
11. Aronsson M, Svennberg E, Rosenqvist M, et al. Cost-effectiveness of mass screening for untreated atrial fibrillation using intermittent ECG recording. Europace. 2015; 17(7): 1023-1029, doi: 10.1093/europace/euv083, indexed in Pubmed: 25868469.

12. Miotla P, Olejniczak P, Futyma K, et al. Can intradetrusor onabotulinumtoxina injections alter heart function in patients with cardiac arrhythmia? J Clin Med. 2018; 7(9): 263, doi: 10.3390/ jcm7090263, indexed in Pubmed: 30205603.

13. Giebel GD, Gissel C. Accuracy of mHealth Devices for Atrial Fibrillation Screening: Systematic Review. JMIR Mhealth Uhealth. 2019; 7(6): e13641, doi: 10.2196/13641, indexed in Pubmed: 31199337.

14. Proietti M, Farcomeni A, Goethals P, et al. Belgian Heart Rhythm Week Investigators. Cost-effectiveness and screening performance of ECG handheld machine in a population screening programme: The Belgian Heart Rhythm Week screening programme. Eur J Prev Cardiol. 2019; 26(9): 964-972, doi: 10.1177/2047487319839184, indexed in Pubmed: 30935219.

15. Hindricks G, Potpara T, Dagres N, et al. 2020 ESC Guidelines for the diagnosis and management of atrial fibrillation developed in collaboration with the European Association of Cardio-Thoracic Surgery (EACTS). Eur Heart J. 2020.

16. Chan PH, Wong CK, Poh YC, et al. Diagnostic performance of a smartphone-based photoplethysmographic application for atrial fibrillation screening in a primary care setting. J Am Heart Assoc. 2016; 5(7): e003428, doi: 10.1161/JAHA.116.003428, indexed in Pubmed: 27444506.

17. Zaprutko T, Zaprutko J, Baszko A, et al. Feasibility of atrial fibrillation screening with mobile health technologies at pharmacies. J Cardiovasc Pharmacol Ther. 2020; 25(2): 142-151, doi: 10.1177/1074248419879089, indexed in Pubmed: 31578088.

18. Godin R, Baranchuk A, Guerra P, et al. Screening for atrial fibrillation via mobile ECG in Canadian primary care practice: a feasibility evaluation. Can J Cardiol. 2018; 34(10): S104, doi: 10.1016/j.cjca.2018.07.250.

19. Lowres N, Neubeck L, Salkeld G, et al. Feasibility and costeffectiveness of stroke prevention through community screening for atrial fibrillation using iPhone ECG in pharmacies. The SEARCH-AF study. Thromb Haemost. 2014; 111(6): 1167-1176, doi: 10.1160/TH14-03-0231, indexed in Pubmed: 24687081.

20. Lowres N, Krass I, Neubeck L, et al. Atrial fibrillation screening in pharmacies using an iPhone ECG: a qualitative review of implementation. Int J Clin Pharm. 2015; 37(6): 1111-1120, doi: 10.1007/s11096-015-0169-1, indexed in Pubmed: 26202627.

21. Evans GF, Shirk A, Muturi P, et al. Feasibility of using mobile ECG recording technology to detect atrial fibrillation in low-resource settings. Glob Heart. 2017; 12(4): 285-289, doi: 10.1016/j. gheart.2016.12.003, indexed in Pubmed: 28302547.

22. Lau JK, Lowres N, Neubeck L, et al. iPhone ECG application for community screening to detect silent atrial fibrillation: a novel technology to prevent stroke. Int J Cardiol. 2013; 165(1): 193-194, doi: 10.1016/j.ijcard.2013.01.220, indexed in Pubmed: 23465249.

23. Hartmann-BP750X-Manual.pdf [Internet]. https://medaval.ie/ docs/manuals/Hartmann-BP750X-Manual.pdf (cited 5 December 2019).

24. AliveCor | FDA-cleared EKG at your fingertips. [Internet]. AliveCor, Inc. https://store.alivecor.com/ (cited 17 January 2019).

25. Kardia now detecting Bradycardia and Tachycardia | AliveCor [Internet]. . https://www.alivecor.com/blog/news/kardia_now_detecting_bradycardia_and_tachycardia/ (cited 18 February 2020).

26. McHugh M. Interrater reliability: the kappa statistic. Biochemia Medica. 2012; 22(3): 276-282, doi: 10.11613/bm.2012.031.

27. Halcox JPJ, Wareham K, Cardew A, et al. Assessment of Remote Heart Rhythm Sampling Using the AliveCor Heart Monitor to Screen for Atrial Fibrillation: The REHEARSE-AF Study. Circulation. 2017; 136(19): 1784-1794, doi: 10.1161/CIRCULATIONAHA.117.030583, indexed in Pubmed: 28851729.
28. Ramkumar S, Nerlekar N, D'Souza D, et al. Atrial fibrillation detection using single lead portable electrocardiographic monitoring: a systematic review and meta-analysis. BMJ Open. 2018; 8(9): e024178, doi: 10.1136/bmjopen-2018-024178, indexed in Pubmed: 30224404.

29. Koshy AN, Sajeev JK, Negishi K, et al. Accuracy of blinded clinician interpretation of single-lead smartphone electrocardiograms and a proposed clinical workflow. Am Heart J. 2018; 205: 149-153, doi: 10.1016/j.ahj.2018.08.001, indexed in Pubmed: 30195576.

30. Desteghe L, Raymaekers Z, Lutin M, et al. Performance of handheld electrocardiogram devices to detect atrial fibrillation in a cardiology and geriatric ward setting. Europace. 2017; 19(1): 29-39, doi: 10.1093/europace/euw025, indexed in Pubmed: 26893496.

31. William AD, Kanbour M, Callahan T, et al. Assessing the accuracy of an automated atrial fibrillation detection algorithm using smartphone technology: The iREAD Study. Heart Rhythm. 2018; 15(10): 1561-1565, doi: 10.1016/j.hrthm.2018.06.037, indexed in Pubmed: 30143448.

32. Selder JL, Breukel L, Blok S, et al. A mobile one-lead ECG device incorporated in a symptom-driven remote arrhythmia monitoring program. The first 5,982 Hartwacht ECGs. Neth Heart J. 2019; 27(1): 38-45, doi: 10.1007/s12471-018-1203-4, indexed in Pubmed: 30523617.

33. Lane DA, McMahon N, Gibson J, et al. Mobile health applications for managing atrial fibrillation for healthcare professionals and patients: a systematic review. Europace. 2020 [Epub ahead of print], doi: 10.1093/europace/euaa269, indexed in Pubmed: 32853369.

34. Mant J, Fitzmaurice DA, Hobbs FD, et al. Accuracy of diagnosing atrial fibrillation on electrocardiogram by primary care practitioners and interpretative diagnostic software: analysis of data from screening for atrial fibrillation in the elderly (SAFE) trial. BMJ. 2007; 335(7616): 380, doi: 10.1136/bmj.39227.551713.AE, indexed in Pubmed: 17604299.

35. Coppetti T, Brauchlin A, Müggler S, et al. Accuracy of smartphone apps for heart rate measurement. Eur J Prev Cardiol. 2017; 24(12): 1287-1293, doi: 10.1177/2047487317702044, indexed in Pubmed: 28464700.

36. Koshy AN, Sajeev JK, Nerlekar N, et al. Smart watches for heart rate assessment in atrial arrhythmias. Int J Cardiol. 2018; 266: 124-127, doi: 10.1016/j.ijcard.2018.02.073, indexed in Pubmed: 29887428.

37. Koshy AN, Sajeev JK, Teh AW. Letter by koshy et al regarding article, „Assessment of remote heart rhythm sampling using the alivecor heart monitor to screen for atrial fibrillation: the REHEARSE-AF study". Circulation. 2018; 137(20): 2191-2192, doi: 10.1161/CIRCULATIONAHA.117.031614, indexed in Pubmed: 29760233.

38. Tassie E, Scotland G, Neilson AR. A model based cost-effectiveness analysis of opportunistic screening for identifying atrial fibrillation with a single lead handheld electrocardiogram monitor in general practices in Scotland. HERU.

39. Young JD, Badowski ME. Telehealth: increasing access to high quality care by expanding the role of technology in correctional medicine. J Clin Med. 2017; 6(2), doi: 10.3390/jcm6020020, indexed in Pubmed: 28208807.

40. Zaprutko T, Kopciuch D, Kus K, et al. Affordability of medicines in the European Union. PLoS One. 2017; 12(2): e0172753, doi: 10.1371/journal.pone.0172753, indexed in Pubmed: 28241019.

41. Zaprutko T, Hromovyk B, Lesyk R, et al. Pharmacies for the pharmacists - Ukrainian Fears and Polish Experiences. Scientia Pharmaceutica. 2020; 88(1): 7, doi: 10.3390/scipharm88010007.

42. Hickey KT, Biviano AB, Garan H, et al. Evaluating the Utility of mHealth ECG Heart Monitoring for the Detection and Management of Atrial Fibrillation in Clinical Practice. J Atr Fibrillation. 2017; 9(5): 1546, doi: 10.4022/jafib.1546, indexed in Pubmed: 29250277.

43. Delgoshaei B, Mobinizadeh M, Mojdekar R, et al. Telemedicine: A systematic review of economic evaluations. Med J Islam Repub Iran. 2017; 31: 113, doi: 10.14196/mjiri.31.113, indexed in Pubmed: 29951414. 